advised about the risk of antimalarial drugs provoking seizures. In view of the risk and the serious consequences if tonic-clonic seizures are provoked, some people with epilepsy may prefer to plan their itinerary so that they avoid the need to take antimalarial drugs.
1 Torrey EF. Chloroquine seizures. JAMA 1968;204:867-70. 2 Kiel FW. Chloroquine suicide. JAMA 1964;190:398-400.

3 Grisham RSC. Central nervous system toxicity of pyrimethamine (Daraprim) in man. Am f Ophthalmol 1962;54:1119-21.

(Accepted 5 May 1988)

\section{Mediastinal haemorrhage: a complication of thrombolytic treatment}

\section{K P Suddes, R D Thomas}

Royal United Hospital, Bath, Avon BA1 3NG K P Suddes, MB, medical registrar

R D Thomas, MD, consultant physician

Correspondence to:

DrThomas. plasminogen activator.

\section{Case report}

Thrombolytic treatment is a major advance in acute myocardial infarction.' The most serious side effect is haemorrhage, and we report a case of mediastinal and pericardial bleeding after the administration of tissue

A 48 year old man presented with severe retrosternal chest pain of two hours' duration. Examination did not show any abnormality. An electrocardiogram showed poor $R$ wave progression and ST segments raised $1.5 \mathrm{~mm}$ in the chest leads. A chest radiograph was normal. Myocardial infarction was thought the most likely diagnosis and he was entered into a trial of thrombolytic treatment. He was given a bolus of 5000 IU heparin and then the trial drug (later shown to be tissue plasminogen activator) over two hours, followed by heparin infusion for 24 hours. Nine hours after admission he developed typical pericardial pain

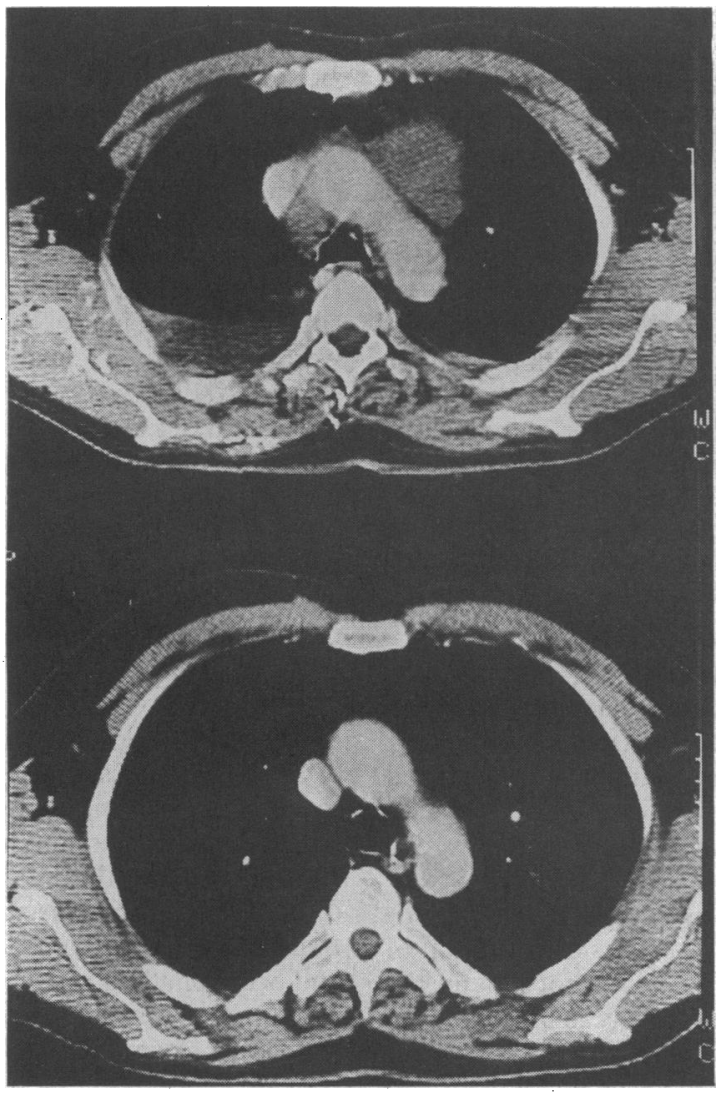

Computed tomograms showing soft tissue mass in anterior mediastinum beside aorta (top) and its resolution three months later (bottom) and was given $50 \mathrm{mg}$ indomethacin orally. Two hours later he became ill with severe chest pain, a heart rate of 140 beats/minute, and a profound fall in systemic blood pressure. The jugular venous pressure was raised $4 \mathrm{~cm}$ above the sternal angle and there was $15 \mathrm{~mm} \mathrm{Hg}$ of paradox. The heart sounds were normal, the electrocardiogram was unchanged, and two dimensional echocardiography showed a small pericardial effusion. The kaolin cephalin clotting time was normal.

We thought that he had pericardial tamponade, but pericardial aspiration produced only $5 \mathrm{ml}$ of heavily bloodstained fluid. His condition improved over the next few hours; further electrocardiograms showed non-specific ST-T change, and serial measurements of cardiac enzyme activity were normal. The next morning a chest radiograph showed appreciable widening of the superior mediastinum. Computed tomography showed a low density mass in the anterior mediastinum, a small pericardial effusion, and a small pleural effusion (figure). As there was a risk of dissecting aortic aneurysm he was transferred to the regional centre for urgent aortography and coronary angiography, which both yielded normal results. Haematological variables, plasma viscosity, viral titres, and autoantibody titres were normal.

At follow up at three months the patient was well and a chest radiograph and computed tomogram were normal.

\section{Comment}

The most serious complication of thrombolytic treatment is bleeding: treatment has to be stopped or a transfusion given in $1-2 \%$ of patients. ${ }^{2}$ This man's primary illness was acute pericarditis, but the main adverse events were iatrogenic mediastinal haemorrhage and pericardial haemorrhage. Mediastinal haemorrhage is rare and is usually the result of trauma or ruptured aortic aneurysm; it rarely occurs in bleeding disorders. Probable mediastinal haemorrhage after intracoronary administration of streptokinase and heparin has been described, ${ }^{3}$ but the patient had been investigated by cardiac catheterisation, itself a cause of mediastinal haemorrhage, and the diagnosis was not proved. In addition, the hazards of thrombolytic treatment in patients with acute pericarditis have been described, with the delayed development of pericardial tamponade. ${ }^{4}$ If thrombolytic treatment becomes more widely used its potential danger in conditions mimicking myocardial infarction must be realised and the complication of mediastinal haemorrhage recognised.

1 Richards T. Seconds may count. Br Med J 1987;295: 198-9.

2 Yusuf $\mathrm{S}$, Collins R, Peto R, et al. Intravenous and intracoronary fibrinolytic therapy in acute myocardial infarction: overview of results on mortality, reinfarction and side-effects from 33 randomized controlled trials. Eur Heart $\mathcal{f} 1985 ; 6: 556-85$

3 Singh S, Ptacin MJ, Bamrah VS. Spontaneous mediastinal haemorrhage; complication of intracoronary streptokinase infusion for coronary thrombosis. Arch Intern Med 1983;143:562-3.

4 Tilley WS, Harston WE. Inadvertent administration of streptokinase to patients with pericarditis. $A m \mathcal{F}$ Med 1986;81:541-4.

(Accepted 3 May 1988) 